\title{
ENVIRONMENTAL INNOVATIVE ACTIVITIES IN SAINT - PETERSBURG STATE TECHNICAL UNIVERSITY (SPbSTU)
}

\author{
A.Ya. Bashkarev, \\ V. A. Popova, \\ V. Yu. Rud' \\ St Petersburg State Technical University, Russia
}

\begin{abstract}
In this article the authors tell about how in present economic conditions goes innovation process in the SPbSTU. The SPbSTU specifity is those, that almost each the innovation project can be applied to the area of environmental ( approximately 60 $\%$ from all total number). Therefore in the review there is the speech about the general concept of the innovation SPbSTU activity and about the link connection innovation politics of SPbSTU with common the St.-Petersburg city Administration innovation politic. Particular examples of innovation activity of Russian State, City Administration structures and the SPbSTU structures. The authors shown examples of their interaction .
\end{abstract}

\section{KEYWORDS}

Environmental, Innovations, SPbSTU, Industrial, Science - technology park.

St.-Petersburg State Technical University (the SPbSTU) has a rich history. It was founded in 1899году.

SPbSTU has become one of the famous scientific and educational establishments in Russia and in the world. From the SPbSTU structure have left and now have an independent life many Universities of St.-Petersburg. There are Financial-economic University, Maritime technical University, Trade-economic University, Construction and Architecture University.

The SPbSTU traditionally lets out a wide profile of the engineers and science officers. It overall educated, perfectly aware engineering and able to apply the knowledge in practice the experts. 
For all period of the SPbSTU existence, in it have received education more than 140000 person.

The most known of the SPbSTU former students are : the Winner of the Nobel premium, academician P. L. Kapitsa; the Winner of the Nobel Premium N. N. Semenov; the Founder of the nuclear weapon, Academician Yu. B. Chariton; the Conducting airdesigners O. K. Antonov and N. N. Polykarpov; the main desighner of the best tank of the Second world war M.l. Koshkin.

The great scientists M.A. Shatelen, A.F. loffe, N.S. Kurnakov, I.N. Voznesenskiy, I.V. Kurchatov, P.N. Lukirsky, A.A. Radtsig was the professors of SPbSTU.

The SPbSTU scientists had been participated in preparation and start of the first in the world of the artificial Sputnic of a planet the Earth, and the first space ship "EAST" ("VOSTOK") with the person onboard too.

In the SPbSTU structure now functions 8 institutes and 13 faculty, 118 faculties and more than 120 scientific laboratories.

more than 2000 lecturers conduct in the SPbSTU educational and scientific work now. There are 96 academicians, 310 professors, more than 1500 doctors of sciences. Together with them in scientific work take a part about 500 post-graduate students, more than 3000 students about 1000 science officers and engineers.

The anstable economic situation, which has developed in Russia last 10 years, hardly helps for educational and scientific progress development in the SPbSTU ( precisely the same as for any other university or scientific institute on the former USSR territory ).

There are :

- difficulties with financing of the scientific projects,

- absence of interest on the part of the potential customers in result of scientific labour,

difficulty of the scientists independently to find financing for their own scientific researches or to find the customer.

This is a characteristic situation for Russia in 1988-1994 years. This situation is a real result of our life. Because the high level of technological development of university sciences and with following introduction of their in an industry was supported by state financing of USSR.USSR needs high technological of manufactures for the military-industrial complex. As soon as the situation has changed, many enterprises was bankrupt. Many large scientists leave Russia, many factories were closed.

St.-Petersburg at this time becomes to the city with great number of discrepancies and disproportions. Main of them is the discrepancy between the large concentration of industrial potential and the ecological capacity of the city territory. There are the reduction of the small waste of manufactures and further decreasing of an ecological conditions. Nevertheless the ecological problems of St.-Petersburg exist already for a long time. This problemsd are a consequence of expansion of the city, decreasing its industry. And also this problems are the result of a great number of economic and social complexities. The pure water in the Neva river and Finnish gulf, fresh air in city, health of the children and adults arise not in result of any order of the city Administrations. They arise because of to long-term and teleological owing policy in most various, but connected among themselves industries both municipal economy, education and science. (BAEV A. S.).

Now it has become clear, that a Russian industry development impossible with the help of shortterm supportive programs only. Now required the new program creations. This programs must be combining, on the one hand, with the requirements of a science and educations developments, and, with other hand, with requirements to development of a market product and a competition 
ability of the russian enterprises.

In St.-Petersburg city Administration today and in the St.-Petersburg city legislative Assembly work the numerous group of the experts. They have not only the high intelligent level, but also well representing importance of innovation sphere development. They attempt to found the innovation city program " The Science of universities for city ". In this program participate all universities of St.-Petersburg. The purpose of the program is following:

- in maintenance of municipal economy of city by modern technological development which are carried out in universities for realization of strategy of socio economic development of city;

- attraction of the investments in technological sphere; preservation and creation of new working places;

- maintenance of a management of city by the information about current and forecast changes of a socio economic and environmental situation in city.

One of the steps of this program is to develope environmentally oriented industry. This item include : 1) to impact to an industry of modern equipments of the control and diagnostics for a condition of industrial objects, 2) environmental safe technologies and materials,3) modern industrial and municipal wastes utilization technologies, 4) optimization of city green zones management. A total cost of environmental part of this program makes about 9000000 roubles (360000 dollars). It is necessary to tell that for realization within the framework of this program was selected the specific projects. The degree of realization of this projects is in frameworks from 50 up to 85 percents. Financing of the program is provided first of all on the basis of existing in St.-Petersburg or recently created innovation - technological parks, which carry out a role of incubators of small business. The world practice has confirmed, that in this case the innovation process progress goes in 4 times faster and in as much time manages cheaper.

In financing of many cities and universities programs accepts active participation The Federal state Russian Fund " Integration of a science and higher school ".

During several last years this fund finance the realization in St.-Petersburg annual " Assembly of the young scientists and specialists of St.-Petersburg " ( AZBEL A.YU.). In this conference each year participate about 300 the best students and young scientists of St.-Petersburg. Within the framework of each Assembly (the annual budget about 900000 roubles) passes a Symposium " Young scientific for environmental of the city ". There are 60-100 young scientists participate in this Symposium each year with the reports. The symposium have traditionally carried out in the SPbSTU. It is the most large symposium of Assembly on amount of the reports.( THE III-RD ASSEMBLY OF YOUNG SCIENTISTS AND SPECIALISTS OF ST.-PETERSBURG)

The best reports from accepted on " The Assembly of the young scientists and specialists of St.Petersburg " 99 " in section " Young scientific for environmental of the city " were recommended to participation in a seminar ECO-TECH'99.

Thus, basic innovation activity in the field of environmental on a macro level (the city level) consists in formation of common policy to support and to develope the innovation projects. This activity must to reach of effective links of interaction of various universities and centres, and to create the system of advertising of the most completed and usefull projects.

The micro level, is in innovation activity in universities of city themselves. At this level each university has the concept of innovation activity running. It is first of all based on the basis of a scientific structure of university (narrow or wide), and ,also, on the scientists and lecturers quality as well as on the educational and scientific laboratories equipment. In this mean of an opportunity of SPbSU to any other universities is much higher. In the list of educational and 
scientific directions of work that provided in SPbSTU, there are all branches and areas of a science. It, influences on the fact, that, for an example, in SPbSTU is not present special environmental faculty. In it there is no necessity, as all institutes and faculty included in SPbSTU structure are large busy in environmental questions.

At the formation of innovation policy the SPbSTU the basic purposes such:

To give an opportunity to finish of scientific labour with the greatest degree of finishing before use of their results in industrial;

To give an opportunity of university youth (students and young researchers) to participate in realization of scientific idea during all its stages;

To establish the wide spectrum of small busines system as the great number of firms, production of which will be in new technology or device invented in SPbSTU;

To attract technological, business and financial resources for increase of training and research SPbSTU divisions opportunities;

To reveal competitive capable industrial technologies and to organize the appropriate new educational programs;

To establish new training mechanisms in SPbSTU for preparation of the necessary experts in the field of innovation activity;

Preservation and development of fundamental scientific directions of the SPbSTU, that will be the potential suppliers of a scientific innovation product;

To create an opportunity for graduate students of the SPbSTU to find a work place at the industrial enterprises - the SPbSTU partners.

For achievement of such purposes it is necessary to establishe a system of university - industrial manufacture, because of the universities researchs are potentially important source for industrial innovations.

Such situation is not new. The legendary roles played by Stanford University and the Massachusetts Institute of Technology in the technological development of Silicon Valley and the Route 128 region, respectively, have been described often in the academic, policy and popular literature (DORFMAN N.; MILLER R., COTE M.; ROGERS E., LARSEN J.). In this cases, the university played a catalytic role, making path breaking discoveries in laboratories which were subsequently commercialized to create jobs and prosperity.

Jaffe's investigation ( JAFFE A.) suggests that the link between academic research and industrial progress is not limited to Silicon Valley and Route 128. Through econometric analysis of US state-level data, Jaffe found a significant and strong effect of total university research upon corporate innovation, as measured by industry patents. This finding held even after Jaffe allowed for industrial research and development (R@D) expenditures.

Using a different methodology, a survey of 76 major firms, Mansfield (MANSFIELD E.) obtained results consistent with Jaffe's. the firms reported that $11 \%$ of new products and $90 \%$ of new processes could not have been developed "without substantial delay" of least one year in the absence of recent academic research. After making some key assumptions. Mansfield then computed a $23 \%$ rate of return to academic research.

In addition, the literature has found that direct university-industry relationships can play an important role in transferring knowledge between firms and university laboratories. For example, a 1982 National Science Board study (NATIONAL SCIENCE BOARD) found survey evidence that large corporations established research relations with universities to access expertise ( both faculty and students) and new technology. Firms enter into university-industry relationships to gain access to students as potential future employees and to aid in product development. 
This firms that participate in university research enjoyed double rate of return to R \&D. (CHEN E.Y.)

However, for useful cooperation in such links with the making enterprise university should spend on a perspectiv scientific direction: a number of the training programs, symposiums, scientific publications, grants, fellowships, scholarships, donations. It is that minimum, having which already it is possible to begin to work in innovation area. The following stage, there are patent licensing, faculty consulting, personal scientific exchanges, sponsored research. The third stage (highest) is in technology park and industrial incubators.

The most advanced forms of university innovation activity are expressed of available working technological park and system of industrial incubators. (CHEN E.Y.)

The SPbSTU is the member of international association of technical universities and will carry out the joint training programs with more than 25 foreign Universities. These training programs are supplemented by the specialized training programs on management R @ D by the projects, running of innovation activity.

A large number of international innovations and the environmental programs were spent with participation of The Twente Universitye, Helsinki University of technology, Mikkele Polytechnik. A lot of ecological literature, created by the authors who are the scientists of the SPbSTU is published. Only on faculty " General Chemistry " in 1998-1999 г.г. has left 7 books, and computer laboratory work on ecological chemistry are created.

In the SPbSTU the large attention at running of innovation activity is given to youth. Though it is clear, that the technological product today is in hands of the people of the senior age. You see, it is received by their labour, degree of his registration up to a level of practical use very frequently is rather low. However, only the authors see and understand the perceptivity of development and way of its use. But a habit of their thinking very frequently prevents them independently to finish of the product idea before their industrial use. At this stage participation of youth, with its opportunity to penetrate in technological sense of development and in conditions of the market to finish it before logic end is very important. Therefore there is no division of innovation activity on to the age categories, and only harmonious association of intelligent forces of all creative generations.( BASHKAREV A.YA., SMIRNOV V.N.)

In 1997 was spent the SPbSTU innovation projects competition. In the tax of the projects the young employees the SPbSTU - the members of Union of the Young Scientists the SPbSTU were busy. Is planned to use youth for realization of the victors projects .

The full schematic illustration of innovation structure of SPbSTU presented on the Figure.

Well known traditional international environmental forum for Baltic region countries "ECOBALTICA" activity the SPbSTU in the field of environmental is interesting by that it is the initiative of youth. These already two conferences (1996 and 1998) were spent in the SPbSTU. In them the young scientists and their supervisors from the Baltic countries participated with the reports. Have accepted participation also scientists from " not Baltic " states: Israel, USA. 


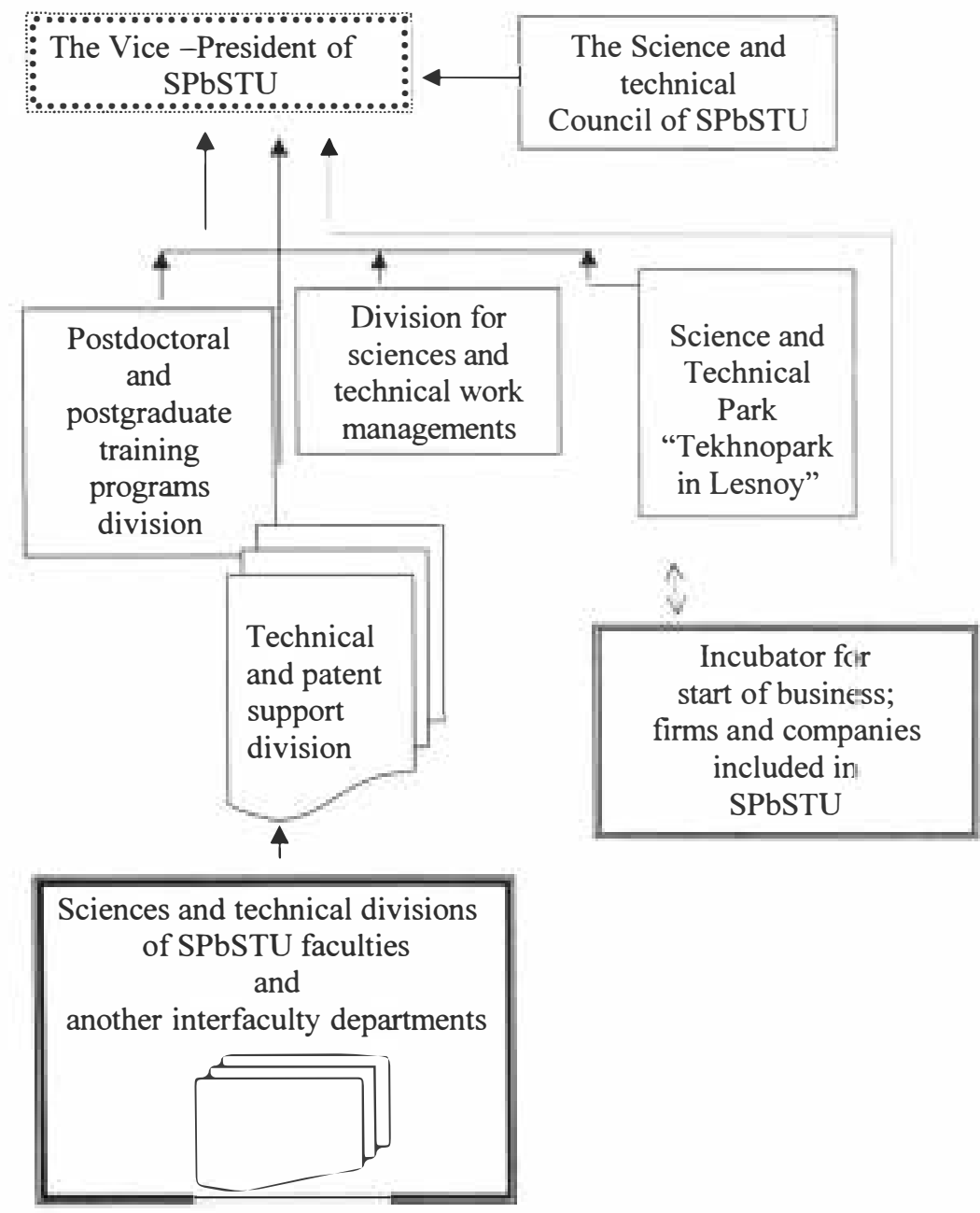

Figure. The schematic illustration of the interrelation in the innovation structure of SPbSTU. 
Realization of "ECOBALTICA" has allowed not only to receive the informations on perspectiv for industrial use of the projects, but also to develop useful scientific communications SPbSTU with Kalmar University and Lund University (Sweden).

Since 1993 in the SPbSTU exists scientific - technological park " Techno park in Lesnoy ". His problem in how to establish strong contacts to research-and-production firms and business by centres, other technological parks. Support of new technologies, creation of the system for supporting of the beginning businessmen and of the technologies transfer ( BASHKAREV A. YA., Vassiliev YU. S., SELEZNEV K. P.)e

His structure is entered with more than 20 research-and-production firms, and innovations structures, Incubator of the beginning businessmen, innovations-technological centre, International office of transfer of technologies. " Techno park in Lesnoy " has about $2000 \mathrm{M} 2$ of the industrial equipped areas. In 1999 the Innovations and technological centre of SPbSTU realized of production on 16000000 roubles, thus was created 28 new working places. Made production is known in Europe and America. Under development of innovation activity Techno park in Lesnoye" has $11360 \mathrm{~m} 2$.

Development of innovation activity in the SPbSTU most likely will further go on a way of increase of direct communications with existing or again forming small making enterprises. At the expense of it a circle of specialities will extend, on which the SPbSTU students will prepare their master science degree, and scientists the SPbSTU will have an opportunity to work by the specific orders of the firms - partners and to be busy of consulting. 


\section{LIST OF REFERENCES}

Azbel A.Yu. (1998).The III-rd Assembly of Young scientists and specialists of St-Petersburg ..Plenary session book.St.-Petersburg City Administration, St.-Petersburg, 50 pp.

Baev A. S. (1997). Environmental situation in ST.-Petersburg in 1996. St.-Petersburg City Administration. St.-Petersburg, $171 \mathrm{pp}$.

Bashkarev A. Ya., Smirnov V. I. (1997) The Main directions of research and labour of new equipments. Abstracts of SPbSTU Conference. St-Petersburg.280.281.

Bashkarev A.Ya., Vassiliev Yu. S., Seleznev K. P. (1995). Innovation technology in traditional and nontraditional energetics.Abstracts of "ENERGETICS'95" Conference.St.-Petersburg, 341.342 .

Chen E. Y. (1994). The evolution of university-industry technology transfer in Hong Kong. Technovation, 14(7).449.459.

Dorfman N. (1983). Route 128: The development of a regional high technology economy. Research Policy 299.316.

Jaffe A. (1989). Real effects of academic research. American Economic Rewiew. 12.957.970.

Mansfield E.(1991). Academic research and industrial innovation. Research Policy.1.12.

Miller R., Cote M. (1987). Growing the next Silicon Valley: A Guide for Successful Regional Planning. D.C. Heath \& Co., Lexington, MA.

National Science Board,(1982). University-Industry Research Relationships:Selected Studies.Report NSB.82.2.

Rogers E., Larsen J.(1984). Silicon ValleyFever. Basic Books, New York.

The III-rd Assembly of Young scientists and specialists of St-Petersburg (1998). The book of abstracts .St.-Petersburg City Administration, St.-Petersburg 152 pp. 